\title{
ОСОБЕННОСТИ САХАРНОГО ДИАБЕТА У ЛЮДЕЙ СТАРШИХ ВОЗРАСТНЫХ ГРУПП, ПЕРЕЖИВШИХ В ДЕТСТВЕ ДЛИТЕЛЬНЬЕ ПЕРИОДЫ ГОЛОДАНИЯ
}

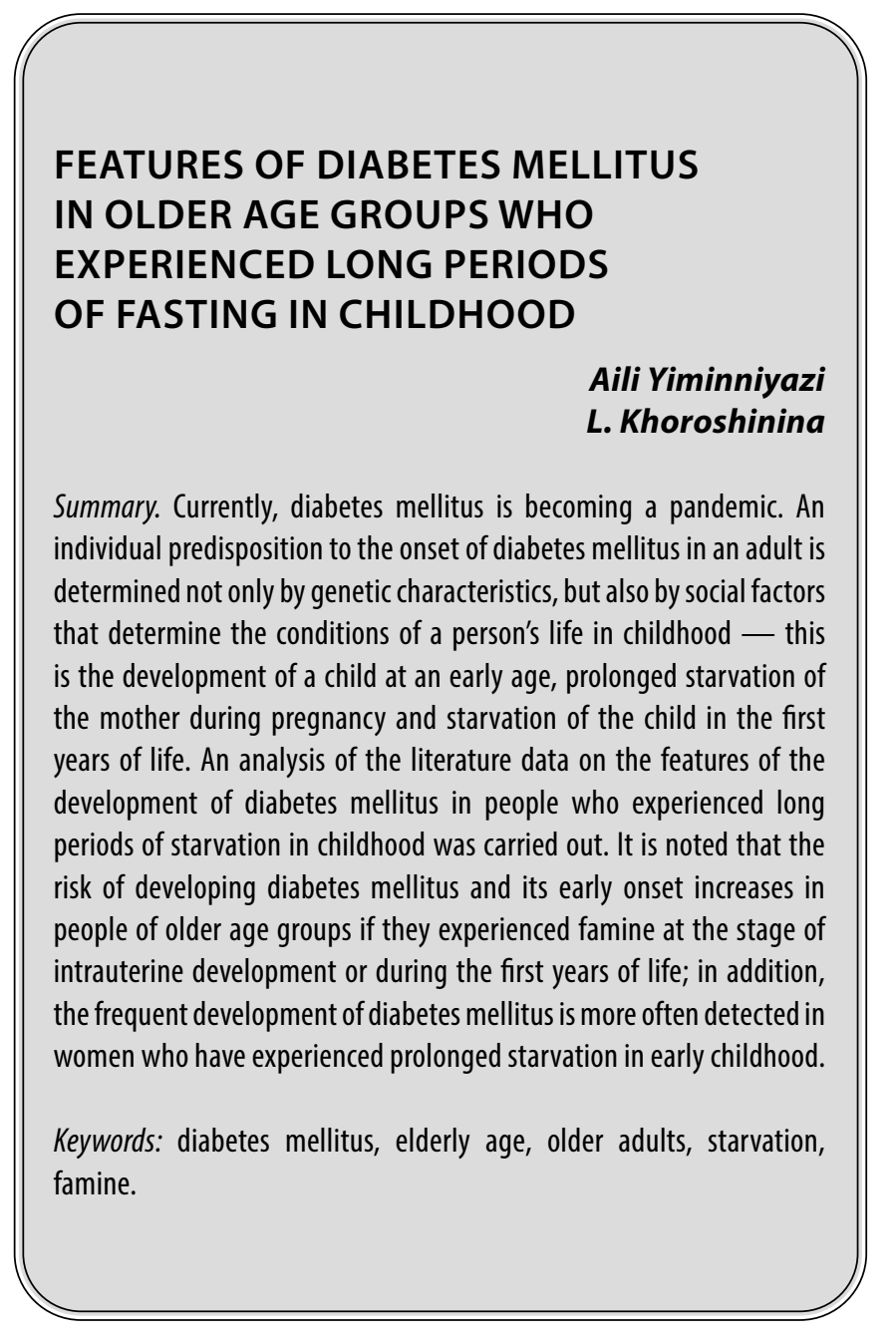

\section{Введение}

B настоящее время сахарный диабет (СД) представляет собой растущую клиническую проблему во всем мире, так, по данным Международной федерации диабета (IDF) в 2015 году во всем мире насчитывалось 415 миллионов взрослых людей, страдающих СД; к 2040 году их число увеличится до 642 миллионов. Большинство стран тратят от 5 до 20\% общих расходов на нужды больных с сахарным диабетом, например, в 2015 году глобальные расходы на лечение СД и его осложнений оценивались в 673 миллиарда долларов и, по прогнозам, вырастут до 802 миллиардов долларов к 2040 году [1].

\author{
Айли Иминьнияцзы \\ Аспирант, Санкт-Петербургский государственный \\ Педиатрический медицинский университет \\ Министерства здравоохранения Российской \\ Фedepauuu \\ ailiphd@mail.ru \\ Хорошинина Лидия Павловна \\ Д.м.н., профессор, Санкт-Петербургский \\ государственный Педиатрический медицинский \\ университет Министерства здравоохранения \\ Российской Федерации \\ solt54@mail.ru
}

Аннотация. В настоящее время сахарный диабет приобретает характер пандемии. Индивидуальная предрасположенность к возникновению сахарного диабета у взрослого человека определяется не только генетическими особенностями, но и социальными факторами, определяющими условия жизни человека в детстве — это развитие ребенка в раннем возрасте, длительные голодания матери во время беременности и голодание ребенка в первые годы жизни. Был проведен анализ литературных данных об особенностях развития сахарного диабета у людей, переживших в детстве длительные периоды голодания. Отмечено, что риск развития сахарного диабета и раннее его возникновение увеличивается у людей старших возрастных групп, если они пережили голод на этапе внутриутробного развития или в течение первых лет жизни; кроме того, частое развитие сахарного диабета чаще выявляется у женщин, переживших длительное голодание в раннем детстве.

Ключевые слова: сахарный диабет, пожилой возраст, старшие возрастные группы, голодание, голод.

Известно, что генетическая предрасположенность частично определяет индивидуальную предрасположенность к СД, но важными факторами глобальной эпидемии сахарного диабета является также и изменение привычного стереотипа питания, о роли которого в развитии хронических соматических заболеваний Всемирная Организация Здравоохранения опубликовала доклад экспертов еще в 1990 году [2], малоподвижный образ жизни [3], длительные периоды голодания в детстве $[4,5,6]$. Во многих исследованиях изучалась связь между условиями жизни в раннем детстве и здоровьем в пожилом возрасте. В ряде научных работ опубликованы результаты изучения состояния здоровья взрослых людей, переживших длительные 
периоды голодания во время событий Второй мировой войны, в частности голландского голода 1944-1945 годов и блокады Ленинграда 1941-1944 годов. Среди взрослых пациентов, подвергшихся голоданию в детском возрасте отмечалась более высокая частота заболеваний органов опорно-двигательного аппарата [7], сообщалось об увеличении частоты онкологических заболеваний $[8,9,10,11,12]$, о частом развитии инсульта, гипертонии, других сердечно-сосудистых заболеваний и состояний $[13,14,15]$, о раннем возникновении и осложнённом течении атеросклероза сонных артерий, аорты и коронарных артерий, $о$ поражениислизистойоболочкижелудка[16] и др.

Целью данной работы является анализ научных публикаций об особенностях сахарного диабета у людей старших возрастных групп, переживших в детстве длительные периоды голодания.

\section{материалы и методы}

Был проведен поиск среди англо- и русскоязычных работ в базах данных CochraneLibrary, PubMed, и e-library, по ключевым словам, (сахарный диабет, пожилой возраст, голодание, голод). Всего проанализировано 26 источника литературы.

\section{Результаты и обсужление}

Работами Д.Баркера и его соавторов (1992) [17] впервые была выявлена связь между внутриутробным голоданием ребенка и повышенным риском развития сахарного диабета во взрослом периоде жизни такого человека. J. Mink et al. (2020) [4] указывают на то, что голод в раннем возрасте во время Второй Мировой войны связан с более высокой вероятностью развития СД 2 типа в более позднем возрасте, так, люди, заявившие, что они хотя бы умеренно страдали от голода, связанного с Второй мировой войной, в детстве или подростковом возрасте имели на 0,7\% (95\% ДИ: 0,073-1,37\%) более высокий риск развития заболевания сахарного диабета второго типа (СД 2) в зрелом возрасте по сравнению со здоровыми людьми. При этом авторы не нашли доказательств влияния голода на вероятность ожирения или избыточной массы тела [4], однако, работами Л.П. Хорошининой и её соавторов $(2002,2020)$ $[6,16]$ доказано, что женщины, пережившие в детстве длительные периоды голодания чаще страдали резко выраженным ожирением (тучностью), по сравнению с как с мужчинами, также переживавшими голодание в детстве, так и с женщинами, избежавшими условий голодного детства. По данным J. Mink et al. (2020) [4] воздействие голода не дает статистически значимого повышения заболеваемости СД 2 у людей старше 5 лет на момент воздействия, что свидетельствует о вероят- ном существовании критических периодов развития организма ребенка во время первых 5 лет его жизни и характерной особенностью таких периодов является повышенная чувствительность к воздействию неблагоприятных факторов. Тем не менее, F. Portrait, E. Teeuwiszen, D. Deeg (2011) отмечали, что тяжелое недоедание в возрасте 11-14 лет среди людей, пострадавших от голода в Голландии, было связано с более высокой вероятностью развития СД в возрасте 60-76 лет [13]. По результатам исследований Л.П. Хорошининой и соавторов (2002) [6] частота сахарного диабета была на порядок выше в группе женщин, переживших в детстве (от 1 года до 16 лет) экстремальные условия существования.

В исследовании Y. Li et al. (2010) [18] сообщается о более высоком риске возникновения гипергликемии у людей, перенесших голод в подростковом периоде. А. F.M. Van Abeelen et al. (2012) [19] опубликовали данные о связи голода с риском развития СД 2: выявлена статистически значимая зависимость «доза-реакция» в возрастных категориях детей 0-9 и 10-17 лет, в то время как в возрастной категории старше 18 лет не было существенной зависимости «доза-реакция». Риск развития СД 2 типа был выше среди женщин, подвергшихся воздействию голода 1944-1945 гг. в Голландии, в возрастной категории старше 18 лет, хотя и не был статистически значимым. J. Mink et al. (2020) [4] обращают внимание на то, что связь между воздействием голода и здоровьем в более позднем возрасте сохранялась, когда в статистическом анализе было скорректировано поведение, влияющее на здоровье (потребление табака, продолжительность сна и диета с точки зрения потребления белков, жиров, углеводов и калорий). Это предполагает прямую связь между воздействием голода в раннем возрасте и риском заболевания в более позднем возрасте независимо от потенциальных изменений в поведении, влияющем на здоровье. При этом переживание голода в детстве положительно коррелировало с потреблением табака и обратно пропорционально со средней продолжительности сна, и достигнутому уровню образования. Данные, полученные другими исследователями при анкетировании несколько сот взрослых людей, свидетельствуют о том, что взрослые люди, пережившие в детстве блокаду Ленинграда достоверно чаще вели здоровый образ жизни, чем их сверстники, жившие во время Великой отечественной войны вне осажденного Ленинграда [6].

D.F. Jyoti, E.A. Frongillo, S.J. Jones (2005) [20] обнаружили, что отсутствие продовольственной безопасности отрицательно влияет на успеваемость школьников. Итак, негативный опыт детства может привести к нездоровому поведению и плохой успеваемости, и в результате к формированию СД. Вне зависимости от наличия 
или отсутствия хронических заболеваний, малолетние жители блокированного Ленинграда чаще, чем их сверстники, переживавшие военное время в другой местности, оставались на второй год обучения в школе, но в последующем чаще получали высшее или среднее специальное образование и чаще были успешными в своей профессии [16].

Отрицательная связь, которую выявили J. Mink et al. (2020) [4] между голодом в раннем возрасте и сном, согласуется с исследованиями K. Bader et al. (2007) [21] и D.P. Chapman et al. (2013) [22], показывающими, что нарушения сна широко распространены у жертв неблагоприятных детских переживаний. Кроме того, van A. F.M. Abeelen et al. (2012) [19] обнаружили, что важные факторы риска СД 2 типа, включая курение, были выше среди женщин, подвергшихся сильному голоду, по сравнению с женщинами, не подвергавшимися воздействию голода. Поправка на такие факторы риска дала несколько заниженные оценки риска развития СД. Работой Л.П. Хорошининой [6] было выявлено, что у людей, переживших в детстве блокаду Ленинграда и, соответственно, длительные периоды голодания, вне зависимости от имеющихся у них заболеваний, отмечались в меньшем проценте случаев такие вредные привычки как табакокурение и злоупотребление алкоголем.

Исследование среди людей, пострадавших от голода в Китае, обнаруживает связь между голодом в раннем детстве и повышенным риском развития метаболического синдрома [23], повышенной концентрацией глюкозы в плазме натощак во взрослой жизни [18].

Исследование ХорошининойЛ.П. и Жаворонковой Н.В. (2008) [5], проведенное у людей, переживших в детстве блокаду Ленинграда, демонстрирует связь между тяжелым недоеданием у детей и повышенной частотой, ранним началом сахарного диабета второго типа у взрослых женщин, причем клинически это заболевание часто протекало без ожирения и артериальной гипертензии. В указанном исследовании [5] у мужчин, в отличие от женщин, переживших в детстве блокаду Ленинграда, не было выявлено повышения частоты СД, что вероятно было обусловлено различными периода- ми повышенной уязвимости регуляторных систем, контролирующих метаболизм у детей разного пола [24].

Неблагоприятные воздействия могут программировать развитие сахарного диабета у взрослых людей как на этапе внутриутробного развития (биологическое программирование), что доказано работами Д. Баркера и его соавторов (1992) [17] и экспериментальными исследованиями M.H. Vickers (2000) [25], так и на этапе постнатального развития (социальное программирование), что впервые было отмечено в работах в Л.П. Хорошининой (2002) [6].

O.G. Zabuga, A.M. Vaiserman (2017) [26] полагают, что эпигенетическая регуляция активности генов считается основным механизмом, связывающим голодание в раннем возрасте и повышенный риск СД 2 типа в пожилом возрасте. Предполагается, что голод во время беременности вызывает стойкие эпигенетические вариации, которые имеют не только адаптивную ценность в раннем постнатальном развитии, но и закладывают основу для метаболических нарушений, включая развитие и особенности течения СД 2 типа в более позднем возрасте. По предположению Л.П. Хорошининой (2002) [6] в результате длительного голодания изменяется функционирование регуляторных систем гипоталамус - гипофиз - надпочечники и в случае определенных обстоятельств у человека (пол, возраст, критические периоды развития, неблагоприятная наследственность) возникают пограничные состояния, которые затем могут перейти в заболевания, в том числе и с развитием сахарного диабета.

Таким образом, воздействие голода в раннем детстве и особенно в течение первых лет жизни увеличивает риск развития сахарного диабета второго типа в пожилом возрасте, при этом отмечается более раннее возникновение и высокая частота развития СД у женщин, переживших длительные периоды голодания. В отношении поведенческих факторов риска единого мнения среди исследователей не отмечено. В существующей научной литературе имеется недостаточно информации о связи длительного голодания в детстве с развитием сахарного диабета у людей в старших возрастных группах.

\section{ЛИТЕРАТУРА}

1. Herman W.H. The global burden of diabetes: an overview //Diabetes mellitus in developing countries and underserved communities. - 2017. - P. 1-5.

2. WHO.: Diet, nutrition and prevention of chronic diseases // Report of a WHO consultations -Geneva, 1990.— № 797. — P. 52-57.

3. Ахмедова Р.М., Софронова Л.В., Владимирова К.Н. Оценка качества жизни подростков, страдающих эндокринными заболеваниями //Педиатр.2016. - T. 7. 一 № . 1.

4. Mink J. et al. Associations between early-life food deprivation during World War II and risk of hypertension and type 2 diabetes at adulthood //Scientific reports. - 2020. - T. 10.— № . 1. - P. 1-9. 
5. Хорошинина Л. П., Жаворонкова Н.В. Голодание в детстве и сахарный диабет в пожилом возрасте //Успехи геронтологии. - 2008. — Т. 21.— № . 4.- - . 684-687.

6. Х Хорошинина Л.П. Голодание в детстве как причина болезней в старости На примере малолетних жителей блокированного Ленинграда. СПб.: Издательский дом СПб МАПО, 2002.- 188с.

7. Рачков Б.М., Юрьев П.В., Макаров В.П. Исходы длительного голодания у лиц, переживших блокаду Ленинграда и членов их семей. Сб. науч. трудов.: «Остеохондрозы и пограничные состояния». СПб., 1993:13-18.

8. Elias S. G. et al. Breast cancer risk after caloric restriction during the 1944-1945 Dutch famine //Journal of the National Cancer Institute. - 2004. - T. 96. №. 7.- P. 539-546.

9. Elias S. G. et al. The 1944-1945 Dutch famine and subsequent overall cancer incidence //Cancer Epidemiology and Prevention Biomarkers. — 2005. — T. 14. № . 8. - P. 1981-1985.

10. Dirx M. J. M. et al. Diet in adolescence and the risk of breast cancer: results of the Netherlands Cohort Study //Cancer Causes \& Control.— 1999. — T. 10.— № . 3.-P. 189-199.

11. Dirx M. J. M. et al. Energy restriction in childhood and adolescence and risk of prostate cancer: results from the Netherlands Cohort Study //American journal of epidemiology.—2001.— T. 154.— № .6. - P. 530-537.

12. Dirx M. J. M. et al. Energy restriction early in life and colon carcinoma risk: Results of the Netherlands Cohort Study after 7.3 years of follow-up //Cancer: Interdisciplinary International Journal of the American Cancer Society. — 2003. - T. 97. — № . 1. — P. 46-55.

13. Portrait F., Teeuwiszen E., Deeg D. Early life undernutrition and chronic diseases at older ages: the effects of the Dutch famine on cardiovascular diseases and diabetes //Social science \& medicine. — 2011.— T. 73.— № . 5.— P. 711-718.

14. Koupil I. et al. Blood pressure, hypertension and mortality from circulatory disease in men and women who survived the siege of Leningrad //European journal of epidemiology.—2007.— - T. 22.— № . 4.—P. 223-234.

15. Sparén P. et al. Long term mortality after severe starvation during the siege of Leningrad: prospective cohort study //Bmj. — 2004.— T. 328. — № . 7430.— P. 11.

16. Хорошинина Л.П., Иванов Д.О. Голодание в детстве и болезни в старости. На примере малолетних жителей блокированного Ленинграда (Издание 2-е, дополненное и исправленное). СПб.: Изд-во СПб ГПМУ, 2020-176с.

17. Barker D.J.P. The fetal origins of diseases of old age. Eur.J.Clin.Nutrit. 1992;46: 3-9.

18. Li Y. et al. Exposure to the Chinese famine in early life and the risk of hyperglycemia and type 2 diabetes in adulthood //Diabetes. — 2010. — T. 59. — № . 10.- P. 2400-2406.

19. van Abeelen A.F. M. et al. Famine exposure in the young and the risk of type 2 diabetes in adulthood //Diabetes. — 2012. — T. 61. — № . 9.— P. 2255-2260.

20. Jyoti D. F., Frongillo E.A., Jones S.J. Food insecurity affects school children's academic performance, weight gain, and social skills //The Journal of nutrition. 2005. - T. 135. — № . 12. - P. 2831-2839.

21. Bader K. et al. Adverse childhood experiences associated with sleep in primary insomnia //Journal of sleep research. — 2007.— T. 16.— № . 3.—P. 285-296.

22. Chapman D. P. et al. Adverse childhood experiences and frequent insufficient sleep in 5 US States, 2009: a retrospective cohort study //BMC public health. 2013. - T. 13.— № . 1.—P. 1-9.

23. Li Y. et al. Exposure to the Chinese famine in early life and the risk of metabolic syndrome in adulthood //Diabetes care. — 2011.— T. 34. — № . 4. — P. 1014-1018.

24. Черноруцкий М.В. Алиментарная дистрофия в блокированном Ленинграде. Л.: Медгиз,1947.

25. Vickers M. H. et al. Fetal origins of hyperphagia, obesity, and hypertension and postnatal amplification by hypercaloric nutrition //American Journal of Physiology-Endocrinology And Metabolism.— 2000.— T. 279.— № . 1.— P. E83-E87.

26. Zabuga 0. G., Vaiserman A.M. Malnutrition in early life and risk of type 2 diabetes: Theoretical framework and epidemiological evidence //Moscow University Biological Sciences Bulletin.— 2017. - T. 72. — № . 2.— P. 37-46.

(с Айли Иминьнияцзы ( ailiphd@mail.ru), Хорошинина Лидия Павловна ( solt54@mail.ru ).

Журнал «Современная наука: актуальные проблемы теории и практики» 